\title{
Scientific Level of Inquiry and Classroom Practices: Exploratory Study in Junior High School Students
}

\author{
Devi Septiani, Astuti Wijayanti, Dhimas Nur Setyawan, Sigit Sujatmika, Tias Ernawati, \\ Widowati Pusporini \\ \{deviseptiani@ustjogja.co.id ${ }^{1}$, astuti.wijayanti@ustjogja.ac.id ${ }^{2}$,dhimas_ns@ustjogja.ac.id ${ }^{3}$, \\ sujatmika1985@gmail.com ${ }^{4}$, tias.ernawati@ustjogja.ac.id ${ }^{5}$,widowati.pusporini@ustjogja.ac.id $\left.{ }^{6}\right\}$ \\ Department of Science Education, University of Sarjanawiyata Tamansiswa, Yogyakarta, \\ Indonesia ${ }^{1,2,3,4,5,6}$
}

\begin{abstract}
The aim of this study is to analyze the relationship between Junior High School students' perception of inquiry level and implementation of scientific and inquiry level in the science classroom. A total of 41 eighth grade students from two classes at Junior High School (JHS) in Yogyakarta were involved in this study. Students were selected through purposive sampling. Classroom observation, interviews, and documentation of views about scientific inquiry were used to determine knowledge of inquiry and implementation inquiry activities. Data were analyzed by descriptive statistic. The findings show that students who received science instruction through the implementation of inquiry activities still manifest difficulties moving from remembering activities into a true inquiry practice.
\end{abstract}

Keywords: Scientific Level, Inquiry Learning.

\section{Introduction}

Science is one of the subjects taught in Junior High School (JHS) and it is one of the basic sciences that is the foundation in individual thinking patterns to be developed into a major support in problem solving, especially with the application of practical science[1][2][3][4]. Science instruction in JHS is learning that aims to provide mastery of the concept as the basis of science[5]. But in the last few years, the motivation of JHS students to study science has declined considerably[6]. This is one of them caused by the factors within the students themselves, namely the emergence of the assumption that science instruction is not the productive lessons they are aiming at, so they only take a science lesson at a minimum. As for one of the external factors, in general, science teaching and learning activities are still conceptual, not contextual, so they are less attractive to students[7]-[9].

Lots of science concepts are expected to be employed as part of problem solving in the form of applied technology trained in schools. Understanding the concept of science is presented both theoretically and practically with a certain time allocation arrangement. Both (theory and practice) are packaged in a structured manner so that JHS students are expected to be able to be accomplished while learning science in the senior high school (SHS). Students have to state the problems related to phenomena, formulas hypotheses, design and perform the experiments, and conduct measurements at SHS[10]-[14][15] 
Learning science means learning everything related to the object of the universe and the phenomena that are in it, living things and life processes, with the scope of the study of living things, matter and their nature, energy and change, and the earth and the universe[12], [13], [16][17]. Science learning really requires supporting activities in the form of practicum and experiments in the laboratory. Science is built with scientific methods. Through the stages of the scientific method obtained scientific products such as concepts, principles, rules, laws, and theories. Thus learning science means it must include science as a product and as a process[12], [14],[13], [18], [19].

Any efforts made by JHS are trying to increase practical activities so that it is comparable to theoretical activities, as a follow up to students directly confronted with real problems that are often found in everyday activities. This activity is to further sharpen the ability of students in preparing skills that are appropriate to the needs of the labor market. Characteristics and levels of ability of JHS students to explore problems are very diverse [20]. Such conditions must be realized by the teachers in junior high school so that they are able to design learning activities that are able to facilitate the diversity of levels of initial mastery of a skill by students[15]. One activity that can be used is practicum activities.

Practicum is a form of process skills approach. For JHS students, there is a practicum that can be used by using the right tools and teaching materials, as well as helping them with understanding the teaching material in the classroom[5]. In addition, for students who have high curiosity, then through practicum, they can find out the answers to their curiosity as a whole.Practicum is a learning process in which students prove and experience themselves, follow the process, observe objects, analyze, prove and draw conclusions about an object, circumstances, and processes of a material learned from natural phenomena, and their interactions[7].

However, not all JHS have adequate laboratories, so not all of the science concepts taught are followed by lab work. To carry out the practicum which is related to the main material taught in the classroom, a set of tools and materials is needed which is sometimes difficult for schools to fulfill[21]. This condition also added to the limited skills of teachers in designing and developing teaching aids or practicum tools in schools. The absence of tools and materials often becomes an obstacle in not doing the practicum, even though the teacher has practical instructions. Therefore, it is very necessary for the science teacher's creativity in finding alternative materials and other tools that can be used so that the practicum can be carried out and the type of activities in accordance with the curriculum. Such conditions hope to create a condition that the implementation of the practicum does not depend on the completeness of laboratory facilities in schools, but enough to use materials and tools that are easily found in everyday life and can be developed by the teacher as the implementer of science learning processes inside and outside of class.

Curiosity and the effort to investigate to get a solution to solve the problem must be an academic culture at the school. Academic culture and local culture that is less supportive will hinder students' learning motivation. Efforts to establish a scientific culture through investigative activities can be conditioned in laboratory activities with inquiry setting.

Students have maximum opportunities in exploring their curiosity through teacherfacilitated learning activities. The concepts of teaching materials learned through direct experience will be relatively easier to store in long-term memory because students feel, experience and are directly involved in these facts. Inquiry opens up opportunities for the implementation of these conditions, whether done inside or outside the classroom. Science instruction that involves inquiry one of them is presented in the form of practicum activities. Inquiry gives students the opportunity to develop process skills (science) so that it acts as a 
scientist in solving a problem in the field . Students are accustomed to doing activities independently in the framework of an investigation to find facts (science). This has an indirect impact on the process skills it has developed well. These skills increasingly form competencies that are useful in developing their skills. These skills include observing, experimenting, collaborating, recording data, measuring, classifying, comparing, interpreting data, analyzing results and communicating findings. Collaboration between teachers and students who learn through independent inquiry activities will develop students' scientific skills .

Science instruction packaged in inquiry format requires the involvement of physical practicum activities in the laboratory or inside and outside the classroom. Students through mentoring teachers in inquiry will have a series of learning experiences, namely: 1) real experience of how scientists conduct the investigation process; 2) see how scientists build the concept of field-based facts; 3) applying scientific methods to solve problems; 4) understanding natural phenomena and reporting the results through communication verbally and in writing; 5) natural science scenarios; and 6) acting as if he were a scientist .

Determining the level of student inquiry is based on the learning cycle applied in learning assisted by questions from the teacher. National Research Council [6] explains that students' abilities in inquiry include the following:

\subsection{Students have the ability to need to conduct a scientific inquiry through the following activities:}

1. Identification of problems that can be overcome by investigation;

2. Making designs and determining scientific investigations;

3. Using tools and techniques to collect, analyze;

4. Interpret data, develop descriptions, explanations, predictions, and modeling using available evidence;

5. Recognize and analyze other explanations and predictions when the evidence obtained is not appropriate;

6. Communication uses scientific procedures and explanations.

\subsection{Students understand scientific inquiry with several attitude indicators as follows:}

1. Each type of investigation has a different problem formulation;

2. Understanding the material and instructions in each investigation;

3. Mathematics is an important aspect ofthe investigation;

4. Technology in analyzing data to improve data accuracy;

5. A scientific explanation based on evidence, an argument that is logical.

The main point of inquiry learning is the understanding that the level of skills and responsibilities can be gradually introduced to students, over time. Introducing skills and responsibilities to students into a multilevel learning. Inquiry learning is learning that develops skills in scientific thinking, explanation,and practice. Inquiry becomes learning that invites students to be active and responsible in the series of investigative activities carried out. The Levels of Inquiry Model of Science Teachingprovides an instructional framework that helps to ensure thatstudents develop a broader range in intellectual andscientific process skills .

The level of inquiry is inquiry learning conducted in stages. Furthermore, levels of inquiry is an instructional approach that systematically encourages the development of 
intellectual and scientific process skills by addressing inquiry in systematic and comprehensive fashion.Learning models that explain the position of the role of teachers and students in each phase of inquiry activities. Inquiry learning is learning based on inquiry activities that require some skills so that the application of inquiry cannot be done in just one type of inquiry. In each level of inquiry contains five phases of sequential activity in the form of observation, manipulation, generalization, verification, and application. Observation is an observation activity that uses the senses. Manipulation is an active discussion activity to determine things that need to be investigated in the activities listed on the students' worksheet. Generalization is an activity that analyzes the results of manipulation and observation to form a new knowledge. This new knowledge is then developed in the verification stage so that it can make predictions, prove from some other information that has been previously owned, and make conclusions from the activities that have been carried out. Furthermore, the application stage is a continuation stage that is related to the results of the conclusions formed through verification activities developed in different situations when students are in class.Therefore, inquiry learning should be done in stages so that students can develop appropriate skills in each phase of inquiry.

Empirical activities involving scientific knowledge and deep concept understanding always lead to inquiry. The form of activity can be described in the inquiry cycle as follows.

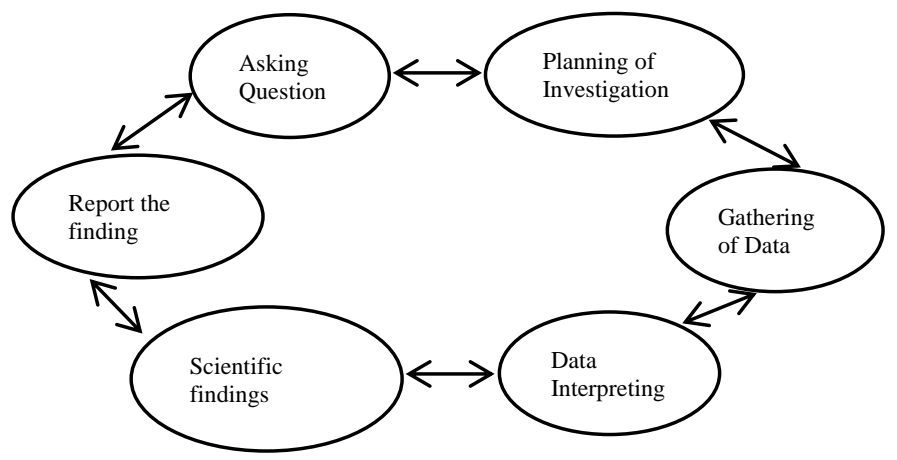

Fig. 1. Cycle of Inquiry

Activities that describe the cycle of inquiry include science practicum conducted in a laboratory, outside the classroom or places where the object of observation is in accordance with the teaching material.Therefore, efforts are needed to improve the quality of learning by knowing the level of student inquiry. The findings about inquiry skills and levels can be used as reference material for the development of science instruction in the classroom.

\section{Method}

As described as the introduction, the research focuses on the field of science education. The type of research is qualitative because this study describes the data from implementing a worksheet that had been developed by researcher. The subject of the research consisted of two classes of Public Junior High School in Yogyakarta on the topic of Ecosystem. The samples are collected by purposive sampling, the mean of classes on chapter examination turn out to be indicator of selection subject. Thus the selection of the classes is relied on the equal abilities 
among them. A total of two classes are 41 students that consisted of 24 female and 17 male students. Both classes use scientific inquiry learning with inquiry levels' worksheet.

The category within qualitative research methodologies is an interactive inquiry that uses a variety of approaches such as case study, grounded theories, and critical studies (James). Case study collects data through observation, discussion, task completions, and self-report from the classroom participants. Moreover, grounded theories and critical studies were piled up by interviews and documentation.

Observation focuses on scientific instruction and activity that delivered in inquiry level phase in the classroom. Moreover, observation is constrained by specific indicators. Researcher and teacher collaborate to observe them. On the other hand, students have to work in a group to get done with activities that organized in the worksheet. There are six activities that divided by three levels of inquiry. Therefore, two activities represent each level of inquiry that had been designed by researcher in worksheet. Each activity modified by inquiry cycle that consisted of five phases of sequential activity in the form of observation, generalization, verification, and application.

The level of the 1st inquiry can be said to be discovery learning or discovery learning, namely, students can develop concepts through basic experiences that have been designed by the teacher. Observation, manipulation, generalization, verification activities have been designed by the teacher. The things students have to do have been planned and stated in the students' worksheet. After conducting planned activities, students are expected to explore investigative findings related to the real world. Activities at the 1 st level of inquiry are the initial activities to introduce students to scientific activities in science learning.

The second level of inquiry can be said to be an interactive demonstration or interactive demonstration related to student activities that can provide explanations and make predictions so that they can lead to conclusions made in the investigation. Observation, manipulation, and generalization activities have been designed by the teacher. The things students have to do have been planned and stated in the students' worksheet. Verification activities carried out by students through making conclusions are directed through discussion questions available in students' worksheet. Students can answer discussion questions after students analyze activities that have been done previously.

The third level of inquiry can be said as an inquiry lesson or inquiry lesson, that is students can identify scientific principles and connect with prior knowledge. The 3rd level of inquiry trains students to combine some prior knowledge. Observation and manipulation activities have been designed by the teacher. However, students must conduct their own generalization and verification activities. This can be seen through the students' answers in the observation table formulated by students so that students are trained to analyze activities that will form new knowledge.

The 4th level of inquiry can be said to be similar to inquiry laboratories or inquiry laboratories, namely, students can build their own law based on measurements of several variables available in the activity. The 4th level of inquiry is an activity that is usually trained in students in grades VIII and IX because students already know and are trained to use measuring instruments and abstract thinking students have also begun to develop so that they have been able to establish their own laws.

The level of the 5th inquiry can be said to be similar to a hypothetical inquiry or hypothetical inquiry, that is students conclude in general for an explanation based on observations of existing phenomena. The 5th level of inquiry can be applied to grade IX students because according to the cognitive development that is generally owned by students, they have been able to design their own investigation activities. 
Then, the discussion is a part of an activity that can be done after learning activities. After students accomplish their activity, they will answer several questions for discussion session that adjusted to inquiry attitude and ability had made by researcher. Furthermore, task completions and self-report are acquired from students' portfolio in a semester. The score of task completions was gathered from two tasks of each level in order that be an achievement of students' attitude and ability inquiry. Indicators of attitude and ability inquiry are adapted to National Research Council as illustrated as the introduction. The score converted to a percentage of each level that categorized to five scale achievement in form of very low, low, medium, high, and very high attitude or ability in the inquiry.

\section{Results And Discussion}

Observation of student characteristics is one of the reference sources for making and developing teaching strategy, teaching method or instructional approach. Characteristics of students observed were cognitive development during teaching-learning process in the science classroom. Cognitive development of grade VIII students especially the ability to think abstractly if judged through daily test results. Based on observations that have been carried out 6 times learning science, this is not so compatible with daily learning activities. The teacher explains the basic material accordingly with student handbooks but students still experience difficulties to answer the practice questions contained in the student handbook. The practice questions are composed of multiple choice questions and brief description. The answers to these questions are available in the student handbook. Male students tend to have difficulty answering because students only listen to the basic material from the teacher, while female students try to find answers by reading back the material in the student handbook. Students' ability to think abstractly and drawing conclusions is still relatively low. The activity continued with an observation of the level of student inquiry.

Initial observation activities are carried out with an explanation in detail by the teacher. Students read the entire explanation found in the worksheet. Students conduct observation activities systematically in accordance with the teacher's direction. activities continued with manipulation, generalization, verification, and application activities. Manipulation activities are activities planning activities to be carried out in the investigation. All planned activities what students do is determined by the teacher. At this level, teacher explain clearly every step stated in the students' worksheet. Students do all activities according to the steps that have been taken explained.

Generalization activities are activities aimed to find material in every inquiry activity. In the basic level this, students are very guided to find material that has been obtained during investigation activities. Students write results observations in accordance with the instructions listed in the worksheet and teacher explanation if needed. Verification activities are a continuation of understanding material such as predictive activities and answer some questions. The questions available are tailored to the material that has been obtained at the generalization stage. In this stage, the teacher is required to direct students to analyze the material obtained through the generalization stage. Application activities are activities to make thinking the right kind of knowledge that has been obtained and the conclusions entered sense of investigation activities. In this activity, students do activities independently without direction. This activity directs to simple investigations in accordance with investigative activities that have been done previously. 
Science instruction that generally should be done with Inquiry learning has not gone well because there is a lack of resources to conduct investigations. Learning science is learning that is done holistically so that it is possible to have integration in science materials with both basic and integrated process skills. Process skills are skills that are not may be mastered by students in one training. This skill is a skill that needs to be trained continuously so that later students will be used to doing the skills correctly. In science learning through the level of inquiry, students conduct investigative activities in sequence according to the cycle of inquiry. In each stage cycle of inquiry, students practice process skills.

The first stage in the level of inquiry is observation so that students practice observing and measuring process skills. The second stage in the level of inquiry is manipulation so that students practice process skills which are looking for space and time relationships and controlling variables. The third stage in the level of inquiry is generalization so that students practice process skills that is interpreting the data. The fourth stage in the level of inquiry is verification so that students can practice process skills namely inferring or make a temporary conclusion on objects observed or activity. The fifth stage is an application so students can train process skills in the form of application skills the knowledge gained becomes more meaningful.

The level of inquiry is a five-level learning model cycle in each level. First level of inquiry level means similar to discovery learning, where students can develop concepts through basic experience. The 2 nd level of inquiry means interactive demonstration related to student activities that can provide explanations and make predictions so that it can lead to the making of conclusions investigation. The level of the 3rd inquiry means something similar to the inquiry lesson or inquiry lessons, that is students can identify scientific principles and or connect with prior knowledge.

Each level of inquiry has two activities is one effort skills training. The level of inquiry uses several skills basic and integrated processes combined in one cycle learning. Determination of the first and second activities in each level using several reference sources related to the seventh grade junior high school science. Determination of the design of the first and second activities in each level pay attention to the level of difficulty of the same activity in accordance with each level.

Observations on the implementation of science instruction in grade 8 were carried out for three days. Every day students do two activities at every level of inquiry. Observation of inquiry skills students are observed by observers with appropriate observation sheets activities were carried out by two classes students. Test subjects come from two different classes with random sampling techniques. The first inquiry level of the first activity with a percentage of $57.14 \%$ for high inquiry attitude and $42.86 \%$ for inquiry attitude is very high. The 1 st level of inquiry in the second activity with a percentage of skills of $42.86 \%$ for high inquiry attitudes and $57.14 \%$ for the attitude of inquiry is very high. Level 2 nd inquiry in the first activity with a percentage of skills of $57.14 \%$ for very low attitudes, $28.57 \%$ for high inquiry attitudes, and $14.28 \%$ for inquiry attitude is very high. The 2 nd level of inquiry in the second activity with percentage of $100 \%$ for inquiry attitude is very high. Level 3rd of inquiry in the first activity with a percentage of skills of $28.58 \%$ for low attitudes and $71.42 \%$ for high inquiry attitudes. This instruction carried out by 64 students at the 3rd level of inquiry in the second activity with skill percentage of $100 \%$ for inquiry attitude is very high.

Inquiry skills are carried out according to learning skills 21 st-century setting. Implementation of thinking skills at the first meeting is $75 \%$, the second meeting is $75 \%$, and the third meeting is $70 \%$. Communication skills were implemented at the first meeting of $66.67 \%$, the second meeting is $100 \%$, and the third meeting is $100 \%$. Collaboration skills 
carried out at the first meeting of $100 \%$, at the second meeting of $100 \%$, and the third meeting amounted to $83.33 \%$. 21st-century learning skills tend to be done when students have enough time to discuss, but the habit of cheating answers friends still often occur. Other difficulties when learning skills did is that students still have not dared to express their opinions, students still have excessive fear if the answer is wrong. These findings inline to OECD while inquiry is a social activity, students need the ability to communicate and form relationships with others and the ability to solve problems and work together [OECD 2015/7].

Communication is one of the process skills that need to be emphasized in science learning [8]. Communication skills are important skills for all professions. Understanding and explanation of nature illustrates science. Explanation of understanding and application of knowledge requires communication skills [9]. Explanation of ideas and results of understanding will be better if communication skills are good. Communication in science can be delivered verbally and nonverbally. The relationship of positive correlation is seen between language clarity and student achievement so that verbal communication becomes an important thing to be considered in the learning process. Verbal communication can show the right understanding of each terminology, explanations relating to each other, signs of topic change, and intonation of delivery. Students will more easily receive material when the teacher is able to explain clearly [10]. In addition, communication is an important skill to support students' social life so that students can interact with the surrounding community according to their capacity. When students have the right communication skills, students will actively build a good social environment in the future.

Communication skills are basic skills that students need to connect with social. According to Son (2015) states that learning activities are basically communication activities because in the learning process, between teachers and students are involved in the process of delivering messages, using media, and receiving messages. The results of investigations that have been carried out will not mean anything if stored in the brain's own memory. Communication can be done orally or in writing. Communication skills that will be trained in student activity sheets cover all four aspects, namely expression, evaluation, response, and negotiation. Students will practice each skill in one topic, namely the life organization system that is packaged through several activities in it. Students express all the results of the activities in the activity sheet through writing the results of observations and analysis in the available columns. This submission can be in the form of numbers, letters, graphics, tables, or pictures. All activities in the student activity sheet facilitate students to express everything that students get in nonverbal form.

Students 'ability in evaluating aspects is reflected through students' attitudes in criticizing observations. Criticizing the results of observations can be observed nonverbally through the accuracy of students choosing the answers to be written in the observation table. In addition, critical observations can be reviewed through the attitudes of students during learning. Students will ask questions related to observations. Students will provide an explanation of the results of the observation. Students respond through discussion activities that are conducted after the investigation activities in the students' worksheet. Indicators of response can be seen through students 'attitudes when responding to each response from the impressions and messages given by peers and students' attitudes when carrying out the activities listed in the students' worksheet.

Negotiating communication skills are observed through students' attitudes when discussing so that mutual agreement can be obtained. The problems available in the worksheets have been compiled as the main material for student discussion so that students are 
trained to discuss in small groups. Students learn to negotiate with themselves and others when discussing in groups.

\section{Conclusion}

Science instruction conducted in the eighth grade of junior high school has tried to train a set of skills patterned in the levels of inquiry. The teacher prepares the LKS in the framework of directing the learning activities of theory and practice towards learning science as scientists do their activities. However, habituation that has not become a learning culture causes students to difficult to change remembering learning patterns to inquiry activities.

\section{References}

[1] E. M. Anderman, G. M. Sinatra, and D. L. Gray, "Studies in Science Education The challenges of teaching and learning about science in the twenty-first century : exploring the abilities and constraints of adolescent learners," Stud. Sci. Educ., vol. 48, no. December 2014, pp. 89-117, 2012.

[2] Sugito, S. M. E. S., Hartono, and Supartono, "Enhancing Students' Communication Skills through Problem Posing and Presentation,” Int. J. Eval. Res. Educ., vol. 6, no. 1, pp. 17-22, 2017.

[3] A. Framework, PISA 2015 Assessment and Analytical Framework. 2017.

[4] E. M. Anderman, G. M. Sinatra, and D. L. L. Gray, "The challenges of teaching and learning about science in the twenty-first century: exploring the abilities and constraints of adolescent learners," Stud. Sci. Educ., vol. 48, no. 1, pp. 89-117, 2012.

[5] Keith S. Taber and Ben Akpan, Science Education. Netherlands: Sense, 2017.

[6] S. Kingful and A. A. Nusenu, "Teachers Motivation in Senior High Schools in Ghana: A case of Ghana Senior High School," J. Educ. Pract., vol. 6, no. 16, pp. 110-122, 2015.

[7] N. G. Lederman, J. S. Lederman, A. Nature, N. G. Lederman, J. S. Lederman, and A. Antink, "International Journal of Education in Mathematics, Science and Technology ( IJEMST ) Nature of Science and Scientific Inquiry as Contexts for the Learning of Science and Achievement of Scientific Literacy Nature of Science and Scientific Inquiry as Conte," Int. J. Educ. Math. Sci. Technol., vol. 1, no. 3, pp. 138-147, 2013.

[8] E. I. D. Ngman-wara, "Ghanaian Junior High School Science Teachers' Knowledge of Contextualised Science Instruction,” J. Curric. Teach., vol. 4, no. 1, pp. 167-178, 2015.

[9] OECD, "PISA 2015 Assessment and Analytical Framework," 2015, p. 202.

[10]Depdiknas, "Peraturan Menteri Pendidikan dan Kebudayaan Republik Indonesia tentang Standar Isi Pendidikan Dasar dan Menengah,” 2013.

[11]R. E. Shope and W. F. Mccomas, "Inquiry-Based Learning for Science , Technology , Engineering, and Math ( Stem ) Programs: A Conceptual and Practical Resource for Educators Teaching Model of Conceptual Change in Action Article information :," 2015.

[12]National Research Council, National Science Education Standards. Washington, DC: National Academy Press, 1996.

[13]P. G. Hewitt and S. Lyons, CONCEPTUAL INTEGRATED SCIENCE, 1st ed. San Francisco: Pearson Addison Wesley, 2007.

[14]N. Koertge, "The nature of scientific inquiry," 1982.

[15]A. M. Ranaweer, "Integrated Science in the Junior Secondary School in Sri Lanka," Paris, 1976. 
[16]E. L. Chiappetta and T. R. Koballa, Science instruction in the middle and secondary schools: Developing fundamental knowledge and skills. 2010.

[17]National Research Council, Taking Science to School: Learning and Teaching Science in Grades K-8. 2007.

[18]C. J. Wenning, "Experimental Inquiry in Introductory Physics Courses," Journal of Physics Teacher Education Online, vol. 6, no. 2. pp. 2-8, 2011.

[19]C. J. Wenning and M. A. Khan, "Levels of Inquiry Model of Science Teaching: Learning sequences to lesson plans," J. Phys. Teach. Educ. Online, vol. 6, no. 2, pp. 17-20, 2011.

[20]P. Tóth, "Learning Strategies and Styles in Vocational Education," vol. 9, no. 3, pp. 195-216, 2012.

[21]Inspectorate Department of Education and Skills, "Science in the Primary School Inspectorate Evaluation Studies," Dublin, 2008. 